Case Report

\title{
Unusual case of congenital fistula between external auditory canal and nasopharynx
}

\author{
Manit M. Mandal*, Ajay J. Panchal, Shanu B. Kher, Harsh G. Dudani, Vidhi D. Shah
}

Department of Otorhinolaryngology, Surat Municipal Institute of Medical Education and Research, Sahara Darwaja, Surat, Gujarat, India

Received: 07 March 2021

Revised: 16 April 2021

Accepted: 19 April 2021

\section{*Correspondence:}

Dr. Manit M. Mandal,

E-mail: drmanit28@gmail.com

Copyright: $\odot$ the author(s), publisher and licensee Medip Academy. This is an open-access article distributed under the terms of the Creative Commons Attribution Non-Commercial License, which permits unrestricted non-commercial use, distribution, and reproduction in any medium, provided the original work is properly cited.

\begin{abstract}
Defects in the development in the neck area of the embryo result in branchial cleft anomalies. Various first branchial cleft anomalies are described in literature including preauricular sinuses, cysts and collaural fistula. In our case study, we document a very unusual case of fistula between floor of external auditory canal and nasopharynx. Such patient requires thorough evaluation and step-wise approach to treat. After clinical examination and radiological evaluation, surgically the fistula was excised in toto via external approach using Modified Blair's incision. In our case, fistulous tract was running from external auditory canal to nasopharynx, running superior and medial to the trunk of facial nerve. No such case is found to be reported in literature after extensive search. Hence, it would be strongly advocated to keep this presentation in the differential diagnosis during evaluation. Also, it is worth mentioning and recommending that a careful radiological examination is a must before approaching for surgery.
\end{abstract}

Keywords: Branchial region abnormalities, Congenital fistula, MR fistulogram, External auditory canal, Nasopharynx

\section{INTRODUCTION}

The branchial arches and clefts are the embryological precursors of the face, neck and pharynx. ${ }^{1}$ Anomalies of the branchial arches and clefts are the second most common congenital lesions of the head and neck in children, with second branchial arch anomalies by far the most common. ${ }^{2}$ Branchial cleft anomalies are the end result of defects in the development in the neck area of the embryo. They may present as cysts, sinus tracts, fistulae or cartilaginous remnants and present with typical clinical and radiological patterns dependent on which arch is involved. ${ }^{1}$ First branchial arch anomalies account for 1$4 \%$ cases with third and fourth branchial arch anomalies being extremely rare. $^{3}$ Various first branchial cleft anomalies are described in literature including preauricular sinuses, cysts and collaural fistula. ${ }^{1}$
A fistula is a communication between two epithelialised surfaces and with regard to branchial arch anomalies, requires communication between a persistent pouch and cleft. If no communication occurs with the inner mucosa or outer skin, then the trapped branchial arch remnant forms a cyst. There are a number of theories proposed to account for the formation of these anomalies, the most widely accepted theory being that they result from incomplete obliteration of the branchial apparatus, primarily the cleft. ${ }^{4}$

In the case of sinuses and fistulae, the pharyngeal membrane and pouch are also implicated.

Here we are reporting a very unusual case of fistula between floor of external auditory canal and nasopharynx. 


\section{CASE REPORT}

An 18-year-old girl presented with complain of intermittent purulent discharge from left ear since long time. After thorough ENT examination, an opening was found in the floor of left ear canal at the junction of cartilaginous and bony parts with pus discharge on pressing the floor of canal. Both tympanic membranes were normal. No opening was found in the neck. MRI left ear fistulogram was done (Figure 1). It showed fistulous tract running from the floor of left external auditory canal to the lateral wall of nasopharynx somewhere near the eustachian tube opening.

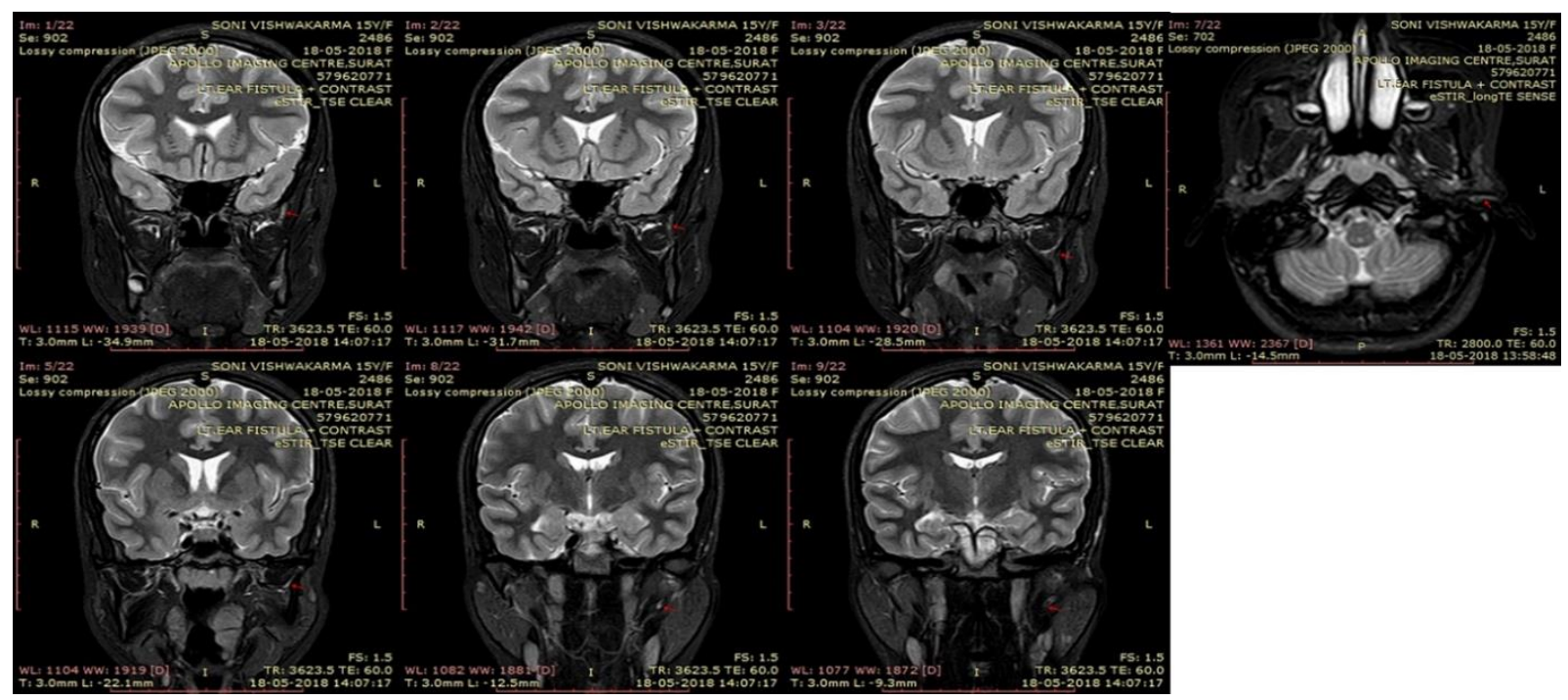

Figure 1: MRI fistulogram showing the unusual tract (marked by red arrow).

We posted the patient for surgical excision which was carried out by Modified Blair's incision under general anesthesia. Intra-operatively the tract was found from the floor of left external auditory canal running downwards and medially as well defined muscular tube-like structure. We dissected the parotid gland from sternocleidomastoid muscle and exposed the facial nerve trunk. Tract was seen going superior and medial to the nerve. It was traced as medially as possible and excised without superficial parotidectomy. Post-operatively facial nerve was normal (Figure 2).

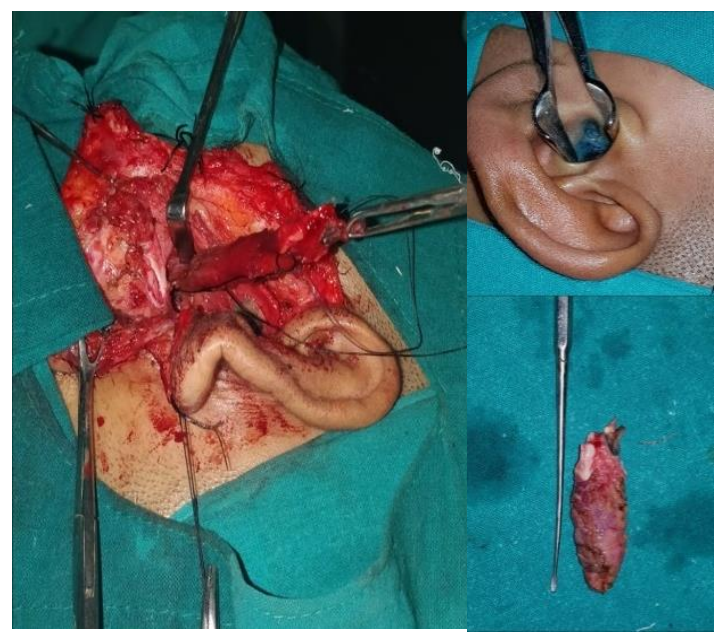

Figure 2: Pre-operative and intra-operative pictures.
Post-operative recovery was uneventful. Patient was followed for 3 weeks after discharge from the hospital. Patient remained asymptomatic and then did not come for follow-up.

Histopathological examination showed stratified squamous epithelium, cartilaginous tissue, muscular and mature adipose tissue along with presence of mononuclear (lymphocytic) infiltration in peri-adnexal regions confirming the fistula (Figure 3 ).

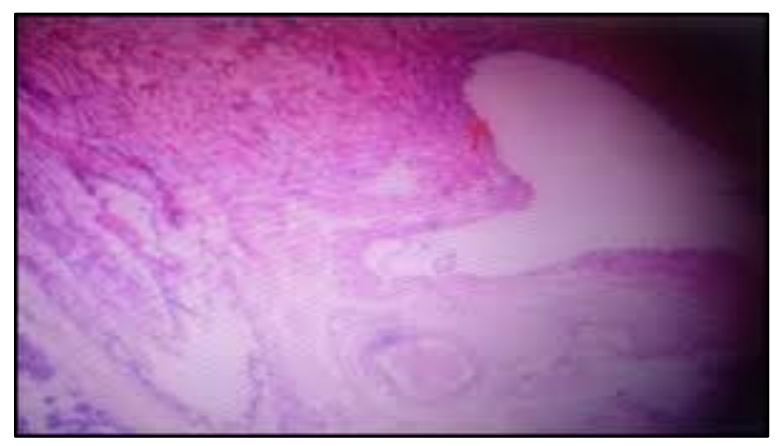

Figure 3: Histopathological examination finding.

\section{DISCUSSION}

During early embryonic life, 6 branchial arches $\left(5^{\text {th }}\right.$ is vestigial), separated from each other by 4 branchial pouches internally and 4 branchial grooves externally, 
develop. Each pouch is lined by endoderm and groove is lined by ectoderm and these grooves and pouches are separated by mesoderm. In fish, this endoderm-mesodermectoderm layer breaks down to form branchial cleft/gill slit. This doesn't occur in man but should it do so, a branchial fistula may occur. In literature, various first branchial cleft anomalies including accessory tragi, preauricular sinuses and cysts, collaural fistulae are reported. Amongst these, collaural fistulae are the least common of the first cleft anomalies. It runs from external auditory meatus or tragal notch down into neck where it opens at a point between angle of mandible and sternocleidomastoid muscle. The fistula is caused by failure of resorption of the ventral part of first branchial groove. The fistulous tract runs through the parotid gland and may pass medial to or lateral to or through the facial nerve branches. This can be excised surgically with potential risk of damage to the facial nerve. As mentioned in literature, it is possible for the endoderm-mesoderm-ectoderm layer between the first branchial groove and the first branchial pouch to disappear so that the two become continuous as a branchial fistula. Should such fistula persist, there'll be an internal opening in the region of eustachian tube orifice and fistula will pass to the surface between internal and external carotid arteries. ${ }^{5,6}$

In our case, fistulous tract was running from external auditory canal to nasopharynx, running superior and medial to the trunk of facial nerve. No such case is found to be reported in literature after extensive search.

\section{CONCLUSION}

Hence, we conclude that when patient presents with discharging opening in the ear canal and no opening is found in the neck, unlike collaural fistula, we must do appropriate investigation including MR fistulogram to exactly find out the deeper extent of the tract. It may extend to deeper structures like nasopharynx, as found in our case.

\section{Funding: No funding sources \\ Conflict of interest: None declared \\ Ethical approval: Not required}

\section{REFERENCES}

1. Adams A, Mankad K, Offiah C, Childs L. Branchial cleft anomalies: a pictorial review of embryological development and spectrum of imaging findings. Insights Imaging. 2016;7(1):69-76.

2. Schoenwolf G, Bleyl S, Brauer P, Francis WP. Larsen's Human Embryology, 4th ed. New York, Churchill Livingston; 2009.

3. Koeller KK, Alamo L, Adair CF, Smirniotopoulos JG. Congenital cystic masses of the neck: radiologicpathologic correlation. Radiographics. 1999;19(1):121-46.

4. Harnsberger HR, Mancuso AA, Muraki AS, Byrd SE, Dillon WP, et al. Branchial cleft anomalies and their mimics: computed tomographic evaluation. Radiology. 1984;152(3):739-48.

5. Kerr A, Adams D, Cinnamond M. Paediatric Otolaryngology. 6th ed. Butterworth-Heinemann; 1997.

6. Watkinson J, Clarke R. Scott-Brown's Otorhinolaryngology And Head And Neck Surgery. 8th ed. Milton: Chapman and Hall; 2018: 466-467.

Cite this article as: Mandal MM, Panchal AJ, Kher SB, Dudani HG, Shah VD. Unusual case of congenital fistula between external auditory canal and nasopharynx. Int J Otorhinolaryngol Head Neck Surg 2021;7:912-4. 